\title{
Application of Weissberger Model for Characterizing the Propagation Loss in a Gliricidia sepium Arboretum
}

\author{
Simeon Ozuomba ${ }^{1, *}$, Enyenihi Henry Johnson ${ }^{2}$, Emmanuel Nsese Udoiwod $^{1}$ \\ ${ }^{1}$ Department of Electrical/Electronic and Computer Engineering, University of Uyo, Nigeria \\ ${ }^{2}$ Department of Electrical/Electronic Engineering, Akwa Ibom State University, Nigeria
}

Copyright $\odot 2018$ by authors, all rights reserved. Authors agree that this article remains permanently open access under the terms of the Creative Commons Attribution License 4.0 International License

\begin{abstract}
In this paper, the Weissberger and the Early ITU propagation loss models were used to characterize the propagation loss for a $3 \mathrm{G}$ cellular network. Particularly, the $3 \mathrm{G}$ network operates at a frequency of $1800 \mathrm{GHz}$ and the case study site is a Gliricidia sepium arboretum which is a Gliricidia sepium Tree Park planted and maintained mainly for scientific study in the annex campus of University of Uyo. Cellmapper app installed on Tecno i5 mobile phone was used to capture the received signal strength; the latitude and longitude of the data capture points, as well as the time and the key cellular network base station data. The relevant mathematical models used to process the measured data and for tuning the Weissberger and the Early ITU propagation loss models were also presented. The Weissberger and the Early ITU propagation loss models were tuned using foliage depth tuning constant. The tuned models prediction performances were evaluated using cross-validation dataset. With the training dataset, the un-tuned Weissberger model had a root mean square (RMSE) value of $21.098 \mathrm{~dB}$ while the tuned Weissberger model had a RMSE of $3.375 \mathrm{~dB}$. Similarly, with the training dataset, the un-tuned Early ITU model had a RMSE of $21.970 \mathrm{~dB}$ while the tuned Early ITU model had a RMSE of $4.019 \mathrm{~dB}$. The tuned Weissberger model with the lowest RMSE was adopted for the prediction of the propagation loss in the case study Gliricidia sepium arboretum. Furthermore, the Weissberger model was evaluated using the cross-validation dataset and it had RMSE of $4.507 \mathrm{~dB}$.
\end{abstract}

Keywords Weissberger Model, Propagation Loss, Foliage Path Loss Model, Gliricidia Sepium, Arboretum

\section{Introduction}

When wireless signal propagates through the atmosphere without any obstruction, it suffers the spreading or free space propagation loss $4,5,6]$. However, when wireless signal propagates through an area covered with vegetation, it suffers an additional loss in its signal strength due to the foliage and obstructions in the signal path $[7,8,9,10,11]$. Consequently, a typical arboretum will cause additional propagation loss to cellular network users working within the arboretum.

Basically, an arboretum is a botanical garden with mainly plants grown for research, conservation and educational purpose $[1,2,3]$. Determination of the received signal strength at any location within the arboretum can be done using some foliage propagation loss models $[12,13,14]$. In this paper, the Weissberger and the Early ITU foliage propagation loss models are used to characterize the propagation loss within an arboretum that consists of mainly Gliricidia sepium trees [15, 16, 17, 18, 19]. The arboretum is located within the annex campus of University of Uyo in Akwa Ibom state, Nigeria.

Most importantly, studies have shown that no propagation loss model can fit every site. As such, in this paper, the focus is to conduct empirical field measurements of the received signal strength within the gliricidia sepium arboretum and then use the field measured data to tune the Weissberger and the Early ITU foliage propagation loss models so that they will provide more accurate estimation of the expected foliage propagation loss that can be experienced by the $1800 \mathrm{GHz}$ wireless signal.

\section{The Case Study Site and Data Collection}

The study was conducted in an arboretum consisting mainly of Gliricidia sepium tree, Figure 1 [20, 21]. The arboretum is located inside University of Uyo annex campus in Uyo metropolis. The Gliricidia sepium trees are about 8 meters high and with average space of 5 meters between adjacent tree stand.

The signal strength of the $3 \mathrm{G}$ cellular network operating at the frequency of $1800 \mathrm{GHz}$ was captured within the arboretum using Cellmapper android app running on Tecno i5 mobile phone. The Cellmapper app enabled the Tecno i5 mobile phone to capture the received signal strength; the 
latitude and longitude of the data capture points as well as the time and the key cellular network base station data. The data collected by the Cellmapper android app in the phone were logged and stored in a text file which was later uploaded to a laptop for further processing and propagation loss analysis. After the field data capture, the base station location (latitude and longitude) was obtained based on the Cellmapper Google map location of the base station which was validated by a physical visit to the base station site. The online Haversine distance calculator [22] was used to determine the distance between the base station and each of the RSSI data capture points specified by their latitude and longitude stored in the text file. Furthermore, each of the measured Received Signal Strength (RSSI) value in $\mathrm{dBm}$ was converted to the measured path loss $\left(P L_{m(d B)}\right)$ using the link budget formula;

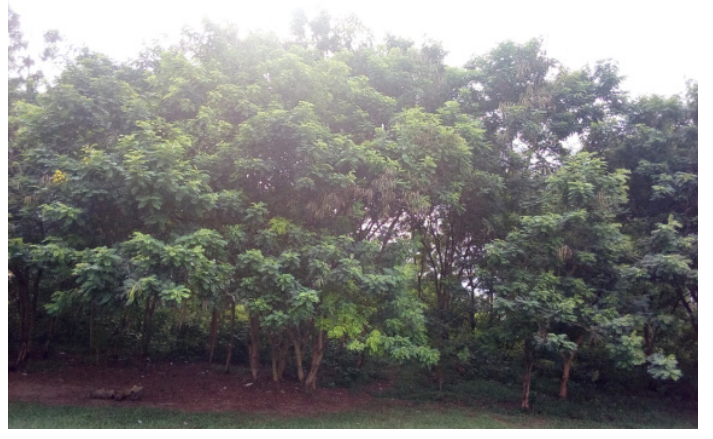

Figure 1. Image of the case study site; the gliricidia sepium arboretum

$$
P L_{m(d B)}=\mathrm{PBTS}+\mathrm{GBTS}+\mathrm{GMS}-\mathrm{RSSI}(\mathrm{dBm})
$$

Where $\mathrm{P}_{\mathrm{BTS}}$ is the transmitter power $(\mathrm{dBm})=20 \mathrm{dBm}$; $\mathrm{G}_{\mathrm{BTS}}$ is the transmitter antenna gain $(\mathrm{dBi})=10 \mathrm{dBm}$ and $\mathrm{G}_{\mathrm{MS}}$ is the receiver antenna gain $(\mathrm{dBi})=10 \mathrm{dBm}$.

\section{The Weissberger-Based Propagation Loss for an Area Covered with Vegetation}

When a wireless signal propagates through an area covered with vegetation the total propagation loss, $P l_{T l}(d B)$ can be obtained as $[15,16,17,18,19]$;

$$
P l_{T l}(d B)=P l_{F S P}(d B)+P l_{\text {Foilage }}(d B)
$$

Where $P l_{F S P}$ is the free space propagation loss and $P l_{\text {Foilage }}$ is the propagation loss due to the foliage. Now, the $P l_{F S P}$ is given as;

$$
P l_{F S P}(d B)=32.5+20 * \log (\mathrm{f})+20 * \log (\mathrm{d})
$$

Where $f$ is the frequency $f$ in $M H z$ and $d$ is the link distance in $\mathrm{km}$. In this paper, the Weissberger model is used to determine the foliage propagation loss. The foliage propagation loss (in $\mathrm{dB}$ ) based on the Weissberger model is given as $P l_{W e i s}(d B)$, where;

$$
\begin{aligned}
& \left\{\begin{array}{c}
0.45 f^{0.284}\left(d_{f}\right) \text { for } 0 \leq d_{f} \leq 14 \mathrm{~m} \\
1.33 f^{0.284}\left(d_{f}\right)^{0.588} \text { for } 14 \leq d_{f} \leq 400 \mathrm{~m}
\end{array}\right. \\
& \text { Where } d_{f} \text { is the depth of foliage along the LOS path in } \\
& \text { meters and } \mathrm{f} \text { is the frequency in GHz Hence, } \\
& \left\{\begin{array}{c}
0.45 F^{0.284}\left(d_{f}\right) \text { for } 0 \leq d_{f} \leq 14 \mathrm{~m} \\
1.33 f^{0.284}\left(d_{f}\right)^{0.588} \text { for } 14 \leq d_{f} \leq 400 \mathrm{~m}
\end{array}\right.
\end{aligned}
$$

$$
P l_{T l}(d B)=32.5+20 * \log (\mathrm{f})+20 * \log (\mathrm{d})+\left\{\begin{array}{r}
0.45 F^{0.284}\left(d_{f}\right) \text { for } 0 \leq d_{f} \leq 14 \mathrm{~m} \\
1.33 f^{0.284}\left(d_{f}\right)^{0.588} \text { for } 14 \leq d_{f} \leq 400 \mathrm{~m}
\end{array}\right.
$$

The model was tuned by using foliage depth tuning constant, $\mathrm{K}_{\mathrm{df}}$, as shown in equation 6 .

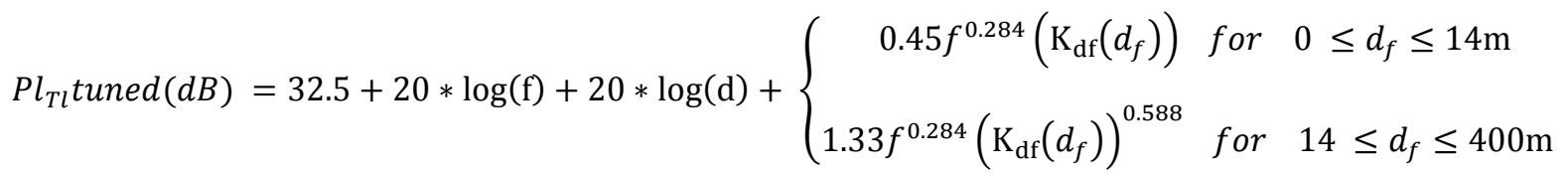

The value of $K_{\mathrm{df}}$ was adjusted iteratively using the Microsoft Excel Solver until the minimum root mean square error (RMSE) was obtained.

\section{The Early Itu -Based Propagation Loss for an Area Covered with Vegetation}

Similar to the Weissberger model, foliage propagation loss (in $\mathrm{dB}$ ) based on the Early ITU model (denoted as $\mathrm{PL}_{\mathrm{ITU}}(\mathrm{dB})$ is given as $[15,17]$ :

$$
\mathrm{PL}_{\text {ITU }}(d B)=\left\{\begin{array}{c}
0.2 f^{0.3}\left(d_{f}\right)^{0.3} \text { for } 0 \leq d_{f} \leq 14 \mathrm{~m} \\
0.2 f^{0.3}\left(d_{f}\right)^{0.6} \text { for } 14 \leq d_{f} \leq 400 \mathrm{~m}
\end{array}\right.
$$

The $\mathrm{PL}_{\mathrm{ITU}}(d B)$ is tuned using a foliage depth factor, $\beta_{f d}$ as follows;

$$
\mathrm{PL}_{\mathrm{ITU}}(d B)=\left\{\begin{array}{c}
0.2 f^{0.3}\left(\left(d_{f}\right) \beta_{f d}\right)^{0.3} \text { for } 0 \leq d_{f} \leq 14 \mathrm{~m} \\
0.2 f^{0.3}\left(\left(d_{f}\right) \beta_{f d}\right)^{0.6} \text { for } 14 \leq d_{f} \leq 400 \mathrm{~m}
\end{array}\right.
$$




\section{Results and Discussion}

The whole measured dataset consisting of distance and RSSI was divided into two datasets obtained by picking one data point and leaving the adjacent data point. One of the two datasets, referred to as the tuning (or training) dataset was used for the tuning of the Weissberger and the
Early ITU propagation loss models while the second dataset, referred to as the validation dataset was used for cross-validation of the tuned propagation loss models. The graph plots of the model tuning (or training) RSSI dataset and the model validation RSSI dataset used for the Weissberger and the Early ITU propagation loss models tuning and validation are shown in Figure 2.

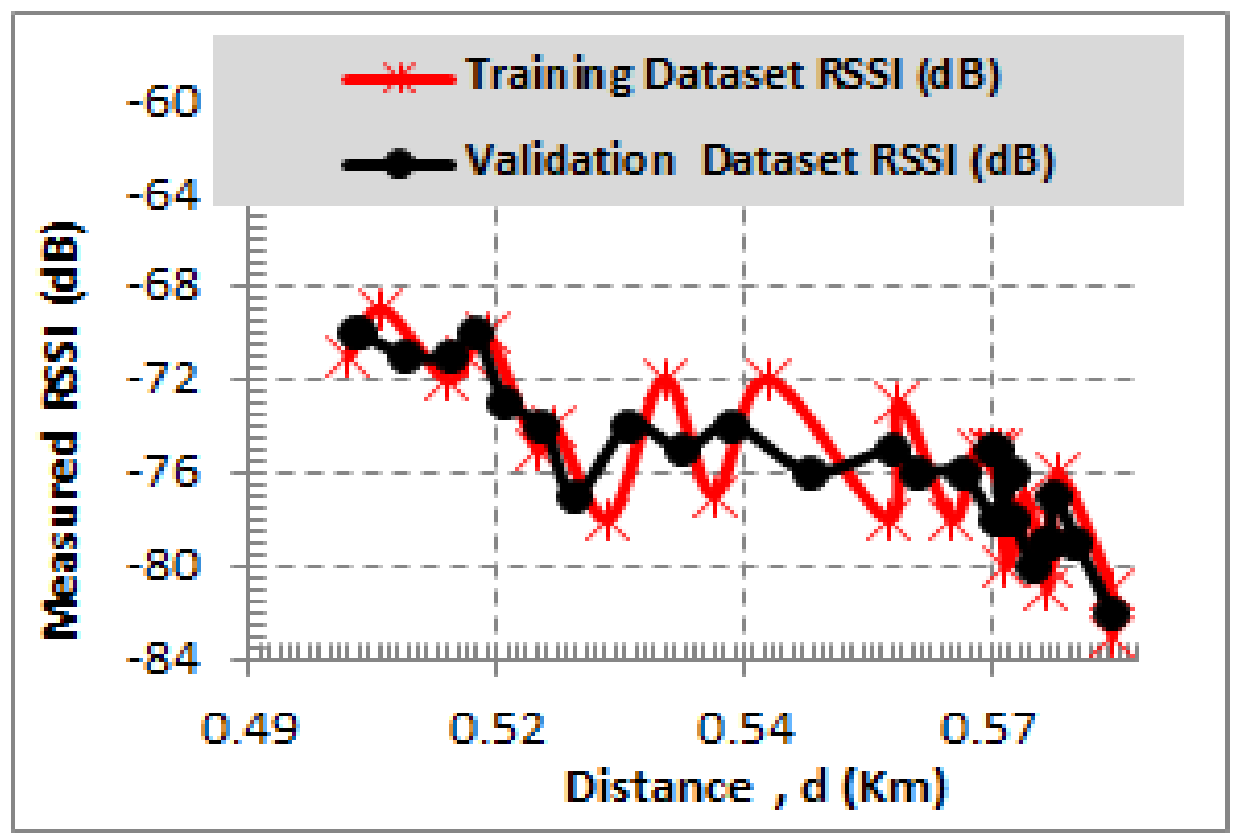

Figure 2. The graph plots of the model tuning (or training) RSSI dataset and the model validation RSSI dataset used for the Weissberger and the Early ITU propagation loss models tuning and validation

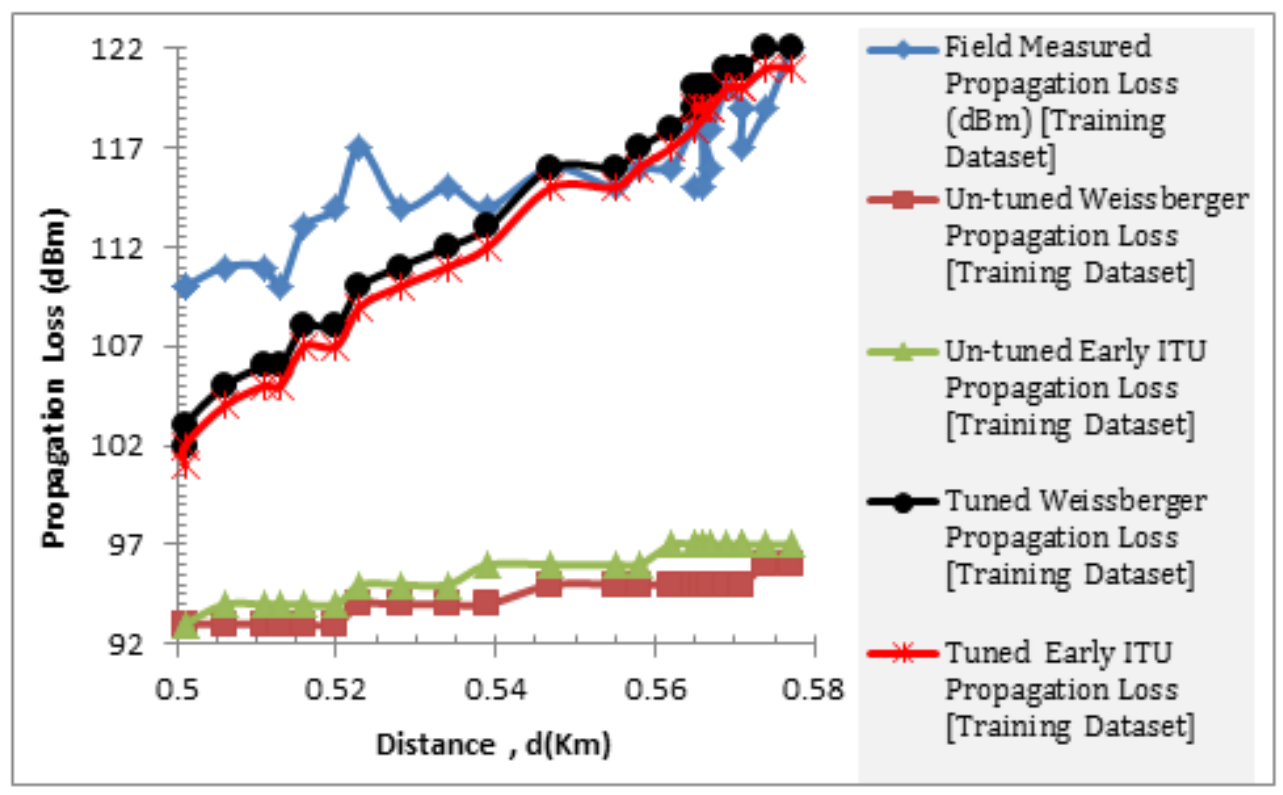

Figure 3. The training dataset results of the propagation loss prediction using the Weissberger and the Early ITU propagation loss models 
The results of the propagation loss prediction using the Weissberger and the Early ITU propagation loss models are shown in Figure 3 for the training dataset. Also, the results of the propagation loss prediction using the Weissberger and the Early ITU propagation loss models are shown in Figure 4 for the validation dataset. Furthermore, the prediction performances in terms of RMSE are shown in Table 1 for the Weissberger and the Early ITU propagation loss models.

The foliage depth tuning constant for the Weissberger model is $\mathrm{K}_{\mathrm{df}}=52.704$ while that of the Early ITU model is $\beta_{\mathrm{fd}}=20.688$. That means, in the tuned Weissberger model, the propagation loss for the vegetation covered area is increasing faster with the foliage depth, df by a factor of 52.704 more than what is specified in the original Weissberger propagation loss model. Similarly, in the tuned Early ITU model, the propagation loss for the vegetation covered area is increasing faster with the foliage depth, df by a factor of 20.688 more than what is specified in the original Weissberger propagation loss model. So, the tuned Weissberger propagation loss model for the Gliricidia Sepium arboretum is given as;

$$
P l_{\text {Tl }} \text { tuned }(d B)=32.5+20 * \log (\mathrm{f})+20 * \log (\mathrm{d})+\left\{\begin{array}{c}
0.45 \mathrm{f}^{0.284}\left(52.704\left(\mathrm{~d}_{\mathrm{f}}\right)\right) \text { for } 0 \leq \mathrm{d}_{\mathrm{f}} \leq 14 \mathrm{~m} \\
1.33 \mathrm{f}^{0.284}\left(52.704\left(\mathrm{~d}_{\mathrm{f}}\right)\right)^{0.588} \text { for } 14 \leq \mathrm{d}_{\mathrm{f}} \leq 400 \mathrm{~m}
\end{array}\right.
$$

Similarly, the tuned Early ITU propagation loss model for the Gliricidia Sepium arboretum is given as;

$$
\mathrm{PL}_{\text {ITU }} \text { tuned }(\mathrm{dB})=\left\{\begin{array}{c}
0.2 \mathrm{f}^{0.3}\left(20.688\left(\mathrm{~d}_{\mathrm{f}}\right)\right)^{0.3} \text { for } 0 \leq \mathrm{d}_{\mathrm{f}} \leq 14 \mathrm{~m} \\
0.2 \mathrm{f}^{0.3}\left(20.688\left(\mathrm{~d}_{\mathrm{f}}\right)\right)^{0.6} \text { for } 14 \leq \mathrm{d}_{\mathrm{f}} \leq 400 \mathrm{~m}
\end{array}\right.
$$

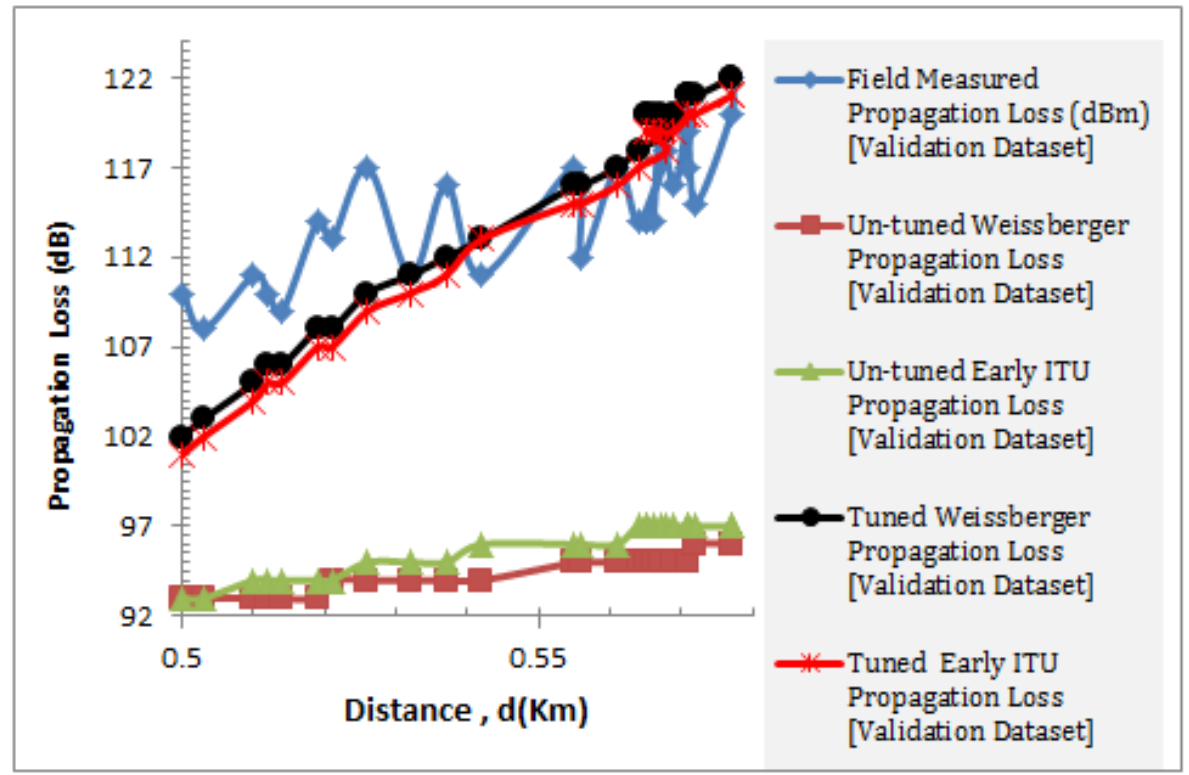

Figure 4. The validation dataset results of the propagation loss prediction using the Weissberger and the Early ITU propagation loss models

Table 1. The prediction performances in terms of RMSE for the Weissberger and the Early ITU propagation loss models

\begin{tabular}{|c|c|c|c|c|}
\hline & $\begin{array}{c}\text { RMSE for the un-tuned } \\
\text { Weissberger model } \\
\text { propagation loss } \\
\text { prediction with } K_{d f}=1\end{array}$ & $\begin{array}{c}\text { RMSE for the un-tuned } \\
\text { Early ITU model } \\
\text { propagation loss } \\
\text { prediction with } \beta_{f d}=1\end{array}$ & $\begin{array}{c}\text { RMSE for the tuned } \\
\text { Weissberger model } \\
\text { propagation loss } \\
\text { prediction with } K_{d f}= \\
52.704\end{array}$ & $\begin{array}{c}\text { RMSE for the tuned } \\
\text { Early ITU model } \\
\text { propagation loss } \\
\text { prediction with } \beta_{f d}= \\
20.688\end{array}$ \\
\hline $\begin{array}{c}\text { RMSE (dB) based on } \\
\text { training dataset }\end{array}$ & 21.098 & 21.970 & 3.375 & 4.019 \\
\hline $\begin{array}{c}\text { RMSE (dB) based on } \\
\text { validation dataset }\end{array}$ & 21.403 & 22.610 & 4.507 & 4.540 \\
\hline
\end{tabular}


The RMSE of the tuned models shows that the tuned Weissberger model with the least RMSE of $3.375 \mathrm{~dB}$ has the best prediction performance for the case study Gliricidia Sepium arboretum. As such, the tuned Weissberger model of Equ 9 is recommended for the prediction of the propagation loss of the $3 \mathrm{G}$ cellular network signal within the Gliricidia Sepium arboretum.

\section{Conclusions}

Development of Weissberger propagation loss model and the Early ITU propagation loss model for an arboretum consisting of Gliricidia Sepium trees is presented. The study was for a $3 \mathrm{G}$ cellular network and it is based on empirical measurements conducted within the Gliricidia Sepium arboretum in the annex campus of University of Uyo. The models were tuned using foliage depth tuning parameters. The Weissberger and the Early ITU propagation loss models gave good prediction performances for the model training dataset and the cross-validation datase. In all, the tuned Weissberger model had the best propagation loss prediction performance.

\section{REFERENCES}

[1] Raven, P. H. (2016). Appreciation of a Great Man: Wu Zhengyi (1916-2013). Plant diversity, 38(6), 262.

[2] Primack, R. B., \& Miller-Rushing, A. J. (2009). The role of botanical gardens in climate change research. New Phytologist, 182(2), 303-313.

[3] Hultine, K. R., Majure, L. C., Nixon, V. S., Arias, S., Búrquez, A., Goettsch, B., ... \& Zavala-Hurtado, J. A. (2016). The role of botanical gardens in the conservation of Cactaceae. BioScience, biw128.

[4] Lavery, M. P., Peuntinger, C., Günthner, K., Banzer, P., Elser, D., Boyd, R. W., ... \& Leuchs, G. (2017). Free-space propagation of high-dimensional structured optical fields in an urban environment. Science Advances, 3(10), e1700552.

[5] Amorim, R., Nguyen, H., Mogensen, P., Kovács, I. Z., Wigard, J., \& Sørensen, T. B. (2017). Radio channel modeling for UAV communication over cellular networks. IEEE Wireless Communications Letters, 6(4), 514-517.

[6] Bennett, R., Henry, P. S., Barzegar, F., Gerszberg, I., Barnickel, D. J., \& Willis III, T. M. (2018). U.S. Patent No. 9,997,819. Washington, DC: U.S. Patent and Trademark Office.

[7] Savage, N., Ndzi, D., Seville, A., Vilar, E., \& Austin, J. (2003). Radio wave propagation through vegetation: Factors influencing signal attenuation. Radio Science, 38(5), 9-1.

[8] Rahim, H. M., Leow, C. Y., Rahman, T. A., Arsad, A., \& Malek, M. A. (2017, November). Foliage attenuation measurement at millimeter wave frequencies in tropical vegetation. In Communications (MICC), 2017 IEEE 13th Malaysia International Conference on (pp. 241-246). IEEE.

[9] Nwawelu, U. N., Nzeako, A. N., \& Ahaneku, M. A. (2012). The limitations of campus wireless networks: A case study of University of Nigeria, Nsukka [Lionet]. International Journal of Networks and Communications, 2(5), 112-122.

[10] Delmelle, E. M., Rogerson, P. A., Akella, M. R., Batta, R. Blatt, A., \& Wilson, G. (2005). A spatial model of received signal strength indicator values for automated collision notification technology. Transportation Research Part C: Emerging Technologies, 13(5-6), 432-447.

[11] Gomes, I. R., Gomes, C. R., Gomes, H. S., \& dos Santos Cavalcante, G. P. (2018). Empirical radio propagation model for DTV applied to non-homogeneous paths and different climates using machine learning techniques. PloS one, 13(3), e0194511.

[12] Estarki, M. D., Hynes, C., Lea, A., \& Vaughan, R. G. (2017, July). A review of the radio wave propagation through vegetation. In Antennas and Propagation \& USNC/URSI National Radio Science Meeting, 2017 IEEE International Symposium on (pp. 801-802). IEEE.

[13] Adewumi, A. S., \& Olabisi, O. (2018). Characterization and Modeling of Vegetation Effects on UHF Propagation through a Long Forested Channel. Progress in Electromagnetics Research, 73, 9-16.

[14] Ghoraishi, M., Takada, J. I., \& Imai, T. (2013). Radio wave propagation through vegetation. In Wave propagation theories and applications. InTech.

[15] Silva, J. C., Siqueira, G. L., \& Castellanos, P. V. G. (2018), Propagation Model for Path Loss through Vegetated Environments at $700-800 \mathrm{MHz}$ Band. Journal of Microwaves, Optoelectronics and Electromagnetic Applications, 17(1), 179-187.

[16] Azevedo, J. A., \& Santos, F. E. (2017). A model to estimate the path loss in areas with foliage of trees. AEU-International Journal of Electronics and Communications, 71, 157-161.

[17] Meng, Y. S., \& Lee, Y. H. (2010). Investigations of foliage effect on modern wireless communication systems: A review. Progress In Electromagnetics Research, 105, 313-332.Castellanos, G. D., \& Teuta, G. (2017, October). Urban-Vegetation ratio evaluation for Path Loss model in Amazonian region for Television Bands. In European Microwave Conference (EuMC), 2017 47th (pp. 699-702). IEEE.

[18] Castellanos, G., \& Teuta, G. (2017, September). Path loss model in amazonian border region for VHF and UHF television bands. In Antennas and Propagation in Wireless Communications (APWC), 2017 IEEE-APS Topical Conference on (pp. 137-140). IEEE.

[19] Elevitch, C. R., \& Francis, J. K. (2006). Gliricidia sepium (gliricidia). Species profile for Pacific Island agroforestry. (Ed. C. R Elevitch). Permanent Agriculture Resources. Hawaii. http://www. traditionaltree. org.[01/09/2011].

[20] Hernandez, Natalia, et al. "Effect of pre-emergent herbicides on the direct sowing of pregerminated seeds of Gmelina arborea Roxb. and Gliricidia sepium (Jacq.) Kunth ex Walp. for establishment of dendroenergetic plantations." 
REVISTA FORESTAL MESOAMERICA KURU-RFMK 15

(2018): 69-80.

[21] Movable Type Scripts (2017) Calculate distance, bearing and more between Latitude/Longitude points. Available at: https://www.movable-type.co.uk/scripts/latlong.html Accesses on 12 November 2018. 